\title{
inventio
}

La génesis de la cultura universitaria en Morelos

Año 15, núm. 37, noviembre 2019

ISSN: 2007-1760 (impreso) 2448-9026 (digital) | DOI: 10.30973/inventio/2019.15.37/4

PENSAMIENTO UNIVERSITARIO

\section{Percepciones de profesores sobre la formación en competencias en psicología}

\section{Karina Amador Soriano}

ORCID: 0000-0002-6928-3083/kariamador@uqroo.edu.mx

Profesora-investigadora, Departamento de Estudios Sociales y Empresariales, Universidad de Quintana Roo, Unidad Académica Cozumel (UQROO)

\section{RESUMEN}

Las universidades enfrentan el reto de formar estudiantes que respondan a las necesidades laborales, pero existen problemáticas alrededor de la formación, que van desde los aspectos personales y académicos hasta los acontecimientos políticos y económicos que suceden a diario y que impactan en el pensamiento de los jóvenes universitarios. El siguiente trabajo parte de una investigación cualitativa que se realizó con docentes de la Licenciatura en Psicología de la Benemérita Universidad Autónoma de Puebla (BUAP). El objetivo para este trabajo es presentar algunas percepciones que tienen los profesores sobre este plan de estudios en cuanto a la formación en competencias en estudiantes de psicología de esta universidad. Los testimonios de los profesores dejaron ver que la falta de especialización y los vacíos en la formación profesional causan deficiencias en los perfiles de egreso y, por ende, en el ámbito profesional.

PALABRAS CLAVE

percepción; competencias; formación; estudiantes de psicología 


\section{Introducción}

Las instituciones de educación superior (IES) presentan constantes problemas al momento de implementar modelos educativos y planes de estudio. Estos documentos integran las mejores intenciones académicas pero, al llevarlos a la práctica, los resultados no suelen ajustarse a lo esperado. Un ejemplo claro es la formación profesional, donde en ocasiones dista la teoría de la práctica, puesto que al egresar y ejercer los docentes no cuentan con las competencias necesarias y no han asumido la práctica que materialice el currículo (Guzmán, 2010).

En 2009, la Facultad de Psicología de la Benemérita Universidad Autónoma de Puebla (BUAP) presentó un nuevo plan de estudios, que parte del Modelo Universitario Minerva (MUM) de esta institución. El programa educativo se constituye por competencias, las cuales están integradas por los conocimientos, habilidades, actitudes y valores requeridos para satisfacer las necesidades éticas, políticas y económicas en el ámbito laboral y social, relacionadas con su justificación y objetivos (BUAP, 2009). Tiene como base los seis pilares de la educación: aprender a conocer, aprender a ser, aprender a hacer, aprender a vivir juntos, aprender a emprender y aprender a desaprender.

La modalidad del desarrollo por competencias no está siendo comprendida y asumida por uno de los principales actores educativos, el docente, lo cual es grave, al ser quien en la práctica materializa el currículo (Guzmán, 2010). Para el presente estudio se planteó identificar la percepción que tienen los profesores con respecto al desarrollo de competencias en la Licenciatura en Psicología de la BUAP, de acuerdo con lo que se establece en el plan de estudios de 2009.

\section{Desarrollo}

Establecer un año específico en que surgió el concepto de competencias en educación es arriesgado. Hasta ahora es difícil encontrar una fecha que precise antecedentes, aunque sí es posible citar como un acercamiento preciso las nociones de sociedad de la información y del conocimiento, sumadas al concepto de globalización, que han generado una serie de exigencias en el ámbito educativo y laboral. Por lo anterior, el contexto socioeconómico mundial y nacional revelan una amplia necesidad de buscar nuevas formas de enfrentar las exigencias globales y el desarrollo tecnológico, ante lo cual la formación por competencias en la educación superior se convierte en una oportunidad para responder a los nuevos retos (Díaz y Arancibia, 2002).

A partir de esta idea se inició una serie de cuestionamientos sobre las funciones de la universidad, que dejaron ver que la falta de especialización y los vacíos en la formación profesional causan deficiencias en los perfiles de egreso, las cuales a su vez se traducen en deficiencia laboral y, por ende, en carencias en la calidad del servicio y el producto.

Plantear el tema de las competencias es adentrarse en una encrucijada que ha llevado a

Año 15, núm. 37, noviembre 2019 
los expertos a debates que en ocasiones resultan en cuestionamientos o, en el mejor de los casos, llevan a establecer que las competencias son una oportunidad para remediar vacíos en la formación integral del estudiante. El concepto de competencia es, por lo tanto, multidimensional y polisémico, ya que incluye distintos niveles como saber y sobre el saber hacer. Las competencias son un conjunto de conocimientos, saber hacer, habilidades y actitudes que permiten a los profesionales desempeñar y desarrollar funciones de trabajo en los niveles requeridos (Zabalza, 2007).

La disciplina que más ha estudiado la percepción es la psicología; sin embargo, a través de los años la sociología y otras áreas de administración se han sumado a su estudio. La percepción hace referencia a la valoración que un individuo hace de una determinada situación social y de su papel o posibilidades en ella (Roca, 1991). La percepción comprende la decodificación o selección de toda información que nos llega del exterior, que reduce la complejidad y facilita su almacenamiento en la memoria con trabajo efectivo de los sentidos (Hernández, Fernández \& Baptista, 2014).

Al igual que en el tema de las competencias, existen vertientes en el tema de la percepción. A partir de una búsqueda exhaustiva, el presente estudio toma como referencia la teoría de la atribución desde el marco de la percepción social, que hoy en día se retoma como un posible método de análisis que explica la valoración o percepción de las personas ante un acontecimiento. Distintos autores han formalizado el referente teórico de la atribución. Para el presente estudio se recurrió a Fritz Heider, quien establece elementos causales para entender la atribución.

Heider establece dos elementos de análisis de la percepción: uno es la causalidad externa, entendida como un atributo externo, es decir, la influencia que determina una opinión (a este elemento también se le conoce como atribución circunstancial y se relaciona con el medio o acciones de otras personas); otro es la causalidad interna, que se traduce en el efecto interior de la persona, que la conduce a una forma de actuación o comportamiento (también se le conoce como atributo disposicional y se relaciona con la personalidad, motivación, autoestima, entre otros) (Heider, 1958, p. 35).

Respecto al perfil de egreso en estudiantes de psicología del plan de estudios de 2009, se establecen competencias, Ilamadas así en este documento, las cuales están compuestas de conocimientos, habilidades, actitudes y valores, que al momento de establecerse se esperaba que los profesores las desarrollarán en el aula. A través de la entrevista semiestructurada se solicitó a los profesores que dieran su opinión respecto a la formación en competencias en estudiantes de psicología.

La estrategia metodológica parte del enfoque cualitativo y fenomenológico. Se realizaron veinte entrevistas a profesores de la Licenciatura en Psicología de la BUAP, entre enero y febrero de 2017. A continuación se exponen algunos datos generales de los profesores que participaron:

Año 15, núm. 37, noviembre 2019 
De los profesores entrevistados, la edad de la mayoría recae entre los 56 y 60 años. Catorce son mayores de 50 años, y entre los seis restantes hay un maestro de 57 años que se jubiló hace un par de años. Este profesor formó parte de la Comisión de Diseño, Evaluación y Seguimiento Curricular de la unidad académica (es decir, la Facultad de Psicología). Dos profesores, de 66 y 69 años, también son jubilados. Uno de ellos también formó parte de esta comisión y el otro fue parte del equipo directivo de la facultad durante el momento en que se gestaba el proyecto de reestructuración del plan de estudios.

De los profesores entrevistados, doce tienen más de veinte años de laborar en la licenciatura, por lo que se interpreta que conocen los cambios curriculares. De los siete de más de treinta años laborando, tres ya se jubilaron y dos cumplen con el requisito de jubilación (35 años de servicio), pero han decidido no hacerlo; a los tres profesores restantes aún les faltan de dos a tres años para poder hacerlo.

Los profesores de la Licenciatura en Psicología se integran en cuatro áreas: clínica, educativa, social y organizacional. De los profesores entrevistados, tres son del área clínica, siete del área educativa, seis del área social y cuatro del área organizacional.

\section{Análisis desde la teoría de la atribución de Heider}

A continuación se exponen los hallazgos respecto a la percepción de los profesores y el desarrollo de competencias, que se precisan en el plan de estudios de psicología.

\section{Causalidad externa (Heider): atributo circunstancial de la formación en competencias}

Con la respuesta de los profesores y a partir de la postura de Heider se puede determinar que el profesor percibe el tema de la formación en competencias como algo que se ha impuesto en el plan de estudios de 2009 pero que éstas en realidad no se asumen en el aula, porque hay factores que se encuentran ausentes, por ejemplo, la capacitación o un trabajo colegiado que permita comprender cómo se desarrollan en el aula los conocimientos, habilidades, actitudes y valores.

Solamente nos dijeron: vas a dar competencias y era como que la definición básica de la competencia [...] más que nada fue como la función de lo que decía en el formato, que una competencia abarca lo que son conocimientos, habilidades y las actitudes, y entonces se refiere a esto, pero no hubo una discusión ni análisis de qué son las competencias [...] realmente no hubo seguimiento (testimonio 1).

Nos dijeron que iban a cambiar los planes de estudio y nos lo cambiaron en papel. Ahora ya no es éste y es éste [...] no hubo trabajo colegiado, no hubo consultas por academia, nada de eso (testimonio 2).

Año 15, núm. 37, noviembre 2019 
El profesor es clave en la organización educativa, y la formación de docentes en el enfoque de competencias es fundamental e indispensable en el proceso de cambio (González y Larraín, 2005). Es nueva la función que cumple el docente en la formación orientada hacia la generación de competencias, pero si el profesor la considera una imposición, puede darse una predisposición al momento de formar al estudiante bajo este enfoque, o bien no sentirá que hay un acompañamiento para la práctica pedagógica.

Sumado a lo anterior, existe otro atributo que es la implicación de las competencias en la formación del estudiante, es decir, cómo las circunstancias institucionales han conducido al desarrollo de las competencias y al choque con la realidad de los profesores que no están de acuerdo en que las competencias sean una opción en educación superior. No hay una apropiación del término competencias y, por lo tanto, no se asumen, lo que puede deberse a los atributos sociales que se le han dado al término.

Este modelo famoso en competencias que a mí en lo personal me parece una estafa, me parece que no aporta nada, eh, es casi... Están implicadas en este modelo concepciones facilistas, hay un facilismo en la enseñanza universitaria que a mí me enoja, porque el estudiante ya no lee. Lo que tiene que entregar son tareítas, con dibujitos y esas cosas, y entonces, ¿qué es lo que lee en la carrera el estudiante? Pedazos de libros. Nunca tiene una visión global de la profesión, no se tiene una posición global (testimonio 1).

Creo que el término de competencias es muy discutible porque no tiene un origen escolar, educativo. Se le ha querido más o menos emparejar la situación pero yo creo que el problema de la educación no está en cumplir o no las competencias o los objetivos o, como dicen pomposamente, el éxito. Yo creo que por ahí no va. Yo tengo otro término, otra manera de pensar cómo se puede desarrollar un sistema educativo con todas las dificultades del mundo porque forma parte de un contexto, forma parte de un sistema, etcétera, pero bueno, yo no comulgo con las competencias como tal (testimonio 2).

En la idea anterior se advierte una falta de conocimiento en general sobre las competencias, un desacuerdo o la puesta en duda de que las competencias puedan ser el eje rector de currículo. El docente es una figura que ejerce un papel mediador entre el alumno y el plan de estudios (Jiménez, 2002), y podría realizar actividades que lleven a mejorar la calidad de la enseñanza, por lo que en la Licenciatura en Psicología, en las generaciones que han llevado el plan de estudios de 2009, se denota la falta de congruencia entre lo establecido y la práctica curricular.

Año 15, núm. 37, noviembre 2019

ISSN: 2007-1760 (impreso) 2448-9026 (digital) | DoI: 10.30973/inventio/2019.15.37/4 


\section{Causalidad interna (Heider): atribución disposicional del papel del docente}

Este elemento hace referencia a la postura interna del profesor a la hora de desarrollar las competencias que marca el perfil de egreso, es decir, cómo el maestro determina su función para asumir el desarrollo de conocimientos, habilidades, actitudes y valores. Desde Heider, se asume la responsabilidad ante eventos causales, en este caso la docencia. Por un lado, el profesor asume que es necesario desempeñar un papel relevante, pero por otro asume las carencias pedagógicas para formar en competencias. En la entrevista se cuestionó el papel del docente en la formación en competencias; a continuación se presentan dos testimonios:

Yo creo que es fundamental [la formación], pero se requiere actualización, entrenamiento, capacitación de los docentes, porque hay muchos rezagados, habemos otros que venimos con nuevas perspectivas (testimonio 1).

Es importante, pero el profesor no puede enseñar una competencia que no tiene, y creo que eso es algo que se tiene que sentar a revisar [...] saber si realmente el profesor hace su función (testimonio 2).

Se observa que el profesor es consciente del papel que asume en la formación; sin embargo, también reconoce que en ocasiones no se logra una innovación en la práctica pedagógica, lo que deja en duda su función. La profesión del psicólogo, como todas las profesiones, tiene la responsabilidad de formar a futuros egresados que respondan a las exigencias del mercado laboral, es decir, egresados que cuenten con un perfil competitivo en el área, pues, de lo contrario, se pueden generar problemáticas que van desde la falta de incorporación laboral hasta la deficiencia en los planes de estudio que no estén cumpliendo con lo estipulado su perfil de egreso.

El egresado de psicología debe estar preparado para actuar bajo las exigencias del medio y debe sobrellevar las diversas relaciones que en esta interacción surjan, con el fin de tener una visión completa de la relación psicología-trabajo, propia de esta disciplina (Herrera, Restrepo, Uribe \& López, 2009). Para llegar a este nivel es necesario valorar y evaluar la práctica del docente, en este caso, del profesor de la Licenciatura en Psicología de la BUAP; de otra manera, se puede estar cayendo en un vacío entre la formación que debiera impartirse para cumplir con las expectativas laborales y la práctica docente como eje clave para el desarrollo de competencias.

\section{Conclusiones}

La percepción de los profesores respecto al desarrollo de competencias en la Licenciatura en Psicología de la BUAP es que éstas son sólo en una formalidad del plan de estudios de 2009, y 
son pocos los profesores que realmente desarrollan de manera integral conocimientos, habilidades, actitudes y valores. Por un lado, el profesor percibe la falta de conocimiento profundo de las competencias en el aula, y por otro, percibe que la formación en competencias es algo que no ha funcionado porque surge de un sector industrial, al afirmar que se pierde el verdadero sentido de la universidad bajo los principios científicos y sociales.

La mayoría de los profesores no aprueba el concepto de competencias. Los hallazgos dieron como resultado que la mayoría de los profesores no está de acuerdo en implementar el modelo de competencias. Esta postura tiene que ver con el hecho de entender que con este modelo se pierde la formación humana o social, puesto que mencionan que el concepto surgió del ámbito empresarial, con una perspectiva del tema distinta del área educativa.

\section{Referencias}

Benemérita Universidad Autónoma de Puebla (2009). Plan de Estudios 2009. Licenciatura en Psicología. Facultad de Psicología. http://www.psicologia.buap.mx/

Díaz, R., Arancibia, V. (2002). El enfoque de las competencias laborales: historia, definiciones y generación de un modelo de competencias para las organizaciones y las personaas. Psykhe, 11(2), 204-214, http://www.psykhe.cl/index.php/psykhe/article/view/433

González, L., Larraín, A. M. (2016). Formación universitaria basada en competencias: aspectos referenciales. Memorias del Seminario Internacional. Universidad del Norte.

Gurmán, J. C. (2010). Una propuesta para formar competencias. Revista Electrónica de Desarrollo de Competencias, 5, 106-122, http://www.educandus.cl/ojs/index.php/fcompetencias/article/viewFile/70/66

Heider, F. (1958). The psychology of interpersonal relations. Willey.

Hernández, R., Fernández, C., Beptista, M. (2014). Metodología de la investigación. McGraw Hill.

Herrera, A. Restrepo, M., Uribe, A., López, C. (2009). Competencias académicas y profesionales del psicólogo. Revista Diversitas, 5(2), http://www.redalyc.org/articulo. oa?id=67916260004

Jiménez, E. (2002). La participación de los académicos en el diseño curricular de planes y programas de estudio en la UNAM. Perfiles educativos, XXIV(96), http://www.redalyc.org/ articulo.oa?id=13209605

Roca, J. (1991). Percepción: usos y teorías. Apunts: Educació Física i Esports, 25, http://www.revista-apunts.com/es/hemeroteca?article $=99$

Zabalza Beraza, M. A. (2007). El trabajo por competencias en la enseñanza universitaria. Cátedra Competencias en Educación Superior. http://ddd.uab.cat/pub/jorinndoc/jorinndoc a2007mgn6.pdf

Año 15, núm. 37, noviembre 2019 